\title{
The overexpression of salivary cytokeratins as potential diagnostic biomarkers in head and neck squamous cell carcinomas
}

\author{
Kai Dun Tang ${ }^{1,2}$, Liz Kenny ${ }^{3,4}$, Chris Perry ${ }^{5}$, Ian Frazer ${ }^{6}$ and Chamindie Punyadeera ${ }^{1,2}$ \\ ${ }^{1}$ The School of Biomedical Sciences, Institute of Health and Biomedical Innovation, Queensland University of Technology, \\ Kelvin Grove, Queensland, Australia \\ ${ }^{2}$ The Translational Research Institute, Woolloongabba, Australia \\ ${ }^{3}$ School of Medicine, University of Queensland, Royal Brisbane and Women's Hospital, Brisbane, Queensland, Australia \\ ${ }^{4}$ Central Integrated Regional Cancer Service, Queensland Health, Brisbane, Queensland, Australia \\ ${ }^{5}$ Department of Otolaryngology, Princess Alexandra Hospital, Woolloongabba, Queensland, Australia \\ ${ }^{6}$ The University of Queensland Diamantina Institute, Translational Research Institute, Woolloongabba, Queensland, Australia \\ Correspondence to: Chamindie Punyadeera, email: chamindie.punyadeera@qut.edu.au \\ Keywords: saliva, cytokeratin, head and neck squamous cell carcinoma, human papillomavirus \\ Received: May 17, $2017 \quad$ Accepted: June 28, $2017 \quad$ Published: July 31, 2017 \\ Copyright: Tang et al. This is an open-access article distributed under the terms of the Creative Commons Attribution License 3.0 \\ (CC BY 3.0), which permits unrestricted use, distribution, and reproduction in any medium, provided the original author and source \\ are credited.
}

\section{ABSTRACT}

Background: Cytokeratin (CK) intermediate filaments are demonstrated to have enormous potential in regulating cellular motility and cancer progression. There are more than 20 divergent CKs that have been identified, of which CK 8, 17, 18 and 19 are reported to be elevated in the tumour biopsies of head and neck cancer squamous cell carcinoma (HNSCC) patients. However, CK expression profiles in the saliva of HNSCC patients have not been investigated. We aim to investigate the mRNA expression profiles of CKs in saliva collected from healthy controls, HPV-negative and -positive HNSCC patients.

Methods: Oral rinse samples were collected from 42 cancer-free healthy controls (age-matched) and patients who have been diagnosed with HPV-negative $(n=20)$ and -positive $(n=48)$ HNSCC.

Results: Here, we report that the mRNA expression profiles of CKs differed in saliva collected from healthy controls and HNSCC patients. The mRNA expression levels of CK 8 and 18 were significantly elevated in saliva collected from HPV-negative HNSCC patients; whilst, CK 17 and 19 were expressed at a higher mRNA level in saliva collected from HPV-positive HNSCC patients compared to healthy controls. Importantly, receiver operating characteristic (ROC) analysis showed salivary CK 8 and 18 to have superior sensitivity and specificity in discriminating the HPV-negative HNSCC patients from healthy controls $(80 \%$ and $86 \%)$ as well as between HPVnegative and -positive HNSCC patients (75\% and $81 \%)$.

Conclusion: In summary, we have demonstrated that an aberrant expression of salivary CKs may serve as a potential non-invasive diagnostic biomarker in HNSCC.

\section{INTRODUCTION}

Head and neck cancer is a heterogeneous group of tumours arising from various anatomic structures including the nasal and oral cavity, oropharynx, larynx and hypopharynx [1]. More than $90 \%$ of these are head and neck squamous cell carcinomas (HNSCC) [2] and is the sixth most common cancer worldwide [3]. The incidence of HNSCC associated with traditional risk factors (tobacco use and alcohol consumption) is declining, whereas high-risk 
human papillomavirus (HPV)-positive HNSCC incidence is increasing in the western world, [4-8] including Australia [9].

Although the major risk factors for HNSCC are identified and have been used as prognostic biomarkers in the recent decades, disappointingly, there is no significant improvement in the overall survival rates of HNSCC $(<50 \%$ survival in five years) compared to other cancer types like breast, colorectal and prostate [10-12]. This may be due to the high frequency of locoregional recurrences, limiting the development of new therapeutic strategies for HNSCC patients. Furthermore, most of these tumours are tiny in the early stages of tumour progression and are located in obscure regions of the head and neck anatomy, leading to misdiagnosis [13]. Therefore, saliva has been championed as the next generation body fluid by virtue of convenience sampling, non-invasive nature and serial sampling capabilities aiming at broader community-based screening [14-17].

Cytokeratins (CKs) are a family of cytoskeletal intermediate filament proteins that are commonly found in epithelial tissues [18]. CKs can be classified into two main groups according to their molecular weight and isoelectric point: Type I and Type II. Type I CKs (9 to 20) are more acidic and have a smaller molecular weight (40 - $64 \mathrm{kDa})$; whereas Type II CKs ( 1 to 8 ) are considered as neutral or basic and have a relatively large molecular weight (52 $68 \mathrm{kDa}$ ) [19]. The expression of CKs can be sub-divided into categories depending on the degree of epithelial cells differentiation and maturation $[20,21]$. For instance, cornified cells express CK 1, 2, 10 and 11; stratified cells express CK 4 and 13; basal cells express CK 5 and 14; hyperproliferative cells express CK 6 and 16 and simple cells express CK 7, 8, 18 and 19 [22-24]. As reported by previous studies, tissue polypeptide antigen (TPA), tissue polypeptide specific antigen (TPS), and CYFRA 21-1 are the most commonly used $\mathrm{CK}$ biomarker in various epithelial cell-associated carcinomas [25-27].

The aberrant expression of $\mathrm{CKs}$ has been reported to be associated with HNSCC tumour development and progression [28-30]. Indeed, these studies have only focused on investigating the diagnostic potential of CKs expression in both tumour biopsies and plasma, not in saliva. We hypothesized that the overexpression of CKs in saliva can be served as a potential diagnostic biomarker to discriminate healthy controls from HPV-negative and -positive patients. The aims of this study were two-fold: firstly, to investigate the mRNA expression profiles of CKs in saliva collected from healthy controls and HNSCC patients. Secondly, to determine the diagnostic potential of salivary CK mRNA expression levels in HNSCC.

\section{RESULTS}

\section{Population characteristics}

Healthy controls $(n=42)$ and HNSCC patients $(n=20$ for HPV-negative HNSCC and $n=48$ for HPV-positive
HNSCC) were recruited in this study (refer to Table 1). Most of the participants were male (70\%) compared with females $(30 \%)$. The mean age for healthy controls were 54 years $(\mathrm{SD}=10$; range $=33-72$ years $)$; HPV-negative HNSCC patients were 60 years $(\mathrm{SD}=11$; range $=20$ 92 years) and HPV-positive HNSCC patients were 63 years $(\mathrm{SD}=13.2$; range $=32-87$ years $)$. The majority ethnicity in healthy controls, HPV-negative and -postive HNSCC patients were Caucasian, 92.9\%, 95\% and 98\%, respectively. Healthy controls were more susceptible to be non-smokers than HPV-negative and -positive HNSCC patients. Healthy controls $(42.9 \%)$ were classified as nonsmokers, whilst $20 \%$ and $37.5 \%$ of HPV-negative and -positive HNSCC patients were non-smokers. About 80\% of HPV-negative HNSCC patients were current and former smokers, whilst current and former smokers in the healthy controls and HPV-positive patients were $45 \%$ and $62 \%$ respectively.

According to the TNM classification system of AJCC for HPV-negative and -positive HNSCC patient staging was as follows: Stage I (5\% and 4.2\%), II ( $0 \%$ and $2.1 \%)$, III (30\% and $10.4 \%)$, IVa (30\% and $70.8 \%)$, IVb $(20 \%$ and $10.4 \%)$ and IVc $(0 \%$ and $2.1 \%)$ respectively. Most cases of HPV-negative and -positive HNSCC patients were diagnosed at an advanced stage IV (49 of $66 ; 72 \%)$. HPV-negative HNSCC cancer sites were mostly oropharyngeal and oral cavity (50\% and 25\%) whilst laryngeal, hypopharyngeal and nasopharyngeal were $5 \%$, $15 \%$ and $5 \%$ respectively. Compared to HPV-negative HNSCC patients, the most common anatomical site found in HPV-positive HNSCC patients were oropharyngeal and oral cavity $(91.7 \%$ and $8.3 \%)$. There were few cases of well differentiated squamous cell carcinoma found in both HPV-negative and -positive HNSCC patients. Most of the HPV-negative (75\%) and -positive (50\%) HNSCC patients were considered as moderate and poor squamous cell carcinoma.

\section{The mRNA expression levels of cytokeratin in saliva collected from healthy controls and HNSCC patients}

Although CK is one of the well-known tumour biomarkers for a number of tumour types including HNSCC, its expression level in saliva still remains to be elucidated. To address this question, we first investigated whether the saliva collected from healthy controls and HNSCC patients express the mRNA levels of CK 8, 13, 17 , 18 and 19. As shown in Figure 1, the mRNA expression levels of CK 17, 18 and 19 was significantly upregulated in saliva collected from HNSCC patients compared to healthy controls, albeit CK 8 and 13 . However, there was only a slightly upregulation of CK 8 mRNA expression level in the saliva collected from HNSCC patients compared to healthy control. Hierarchical clustering analysis revealed that the CKs mRNA expression patterns 


\begin{tabular}{|c|c|c|c|}
\hline & \multirow[b]{2}{*}{ Controls } & \multicolumn{2}{|c|}{ HNSCC Patients } \\
\hline & & HPV-negative & HPV-positive \\
\hline & $(n=42)$ & $(n=20)$ & $(n=48)$ \\
\hline \multicolumn{4}{|l|}{ Gender } \\
\hline Male & $29(69.0)$ & $16(80.0)$ & $46(95.8)$ \\
\hline Female & $13(31.0)$ & $4(20.0)$ & $2(4.2)$ \\
\hline \multicolumn{4}{|l|}{ Age (years) } \\
\hline$<50$ & $13(30.9)$ & $2(10.0)$ & $7(14.6)$ \\
\hline $50-60$ & $17(40.5)$ & $4(20.0)$ & $17(35.4)$ \\
\hline$>60$ & $12(28.6)$ & $14(70.0)$ & $24(50.0)$ \\
\hline \multicolumn{4}{|l|}{ Race and ethnicity } \\
\hline Caucasian & $39(92.9)$ & $19(95.0)$ & $47(98.0)$ \\
\hline Other & $3(7.1)$ & $1(5.0)$ & $1(2.0)$ \\
\hline \multicolumn{4}{|l|}{ Smoking status } \\
\hline Smokers & $4(9.5)$ & $5(25.0)$ & $4(8.3)$ \\
\hline Ex-smoker & $15(35.7)$ & $11(55.0)$ & $26(54.2)$ \\
\hline Non-smoker & $18(42.9)$ & $4(20.0)$ & $18(37.5)$ \\
\hline $\mathrm{N} / \mathrm{A}$ & $5(11.9)$ & $0(0)$ & $0(0)$ \\
\hline \multicolumn{4}{|l|}{ Tumour characteristics } \\
\hline AJCC TNM Stage I & & $1(5.0)$ & $2(4.2)$ \\
\hline Stage II & & $0(0)$ & $1(2.1)$ \\
\hline Stage III & & $6(30.0)$ & $5(10.4)$ \\
\hline Stage IVa & & $6(30.0)$ & $34(70.8)$ \\
\hline Stage IVb & & $3(20.0)$ & $5(10.4)$ \\
\hline Stage IVc & & $0(0)$ & $1(2.1)$ \\
\hline $\mathrm{N} / \mathrm{A}$ & & $3(15.0)$ & $0(0)$ \\
\hline \multicolumn{4}{|l|}{ Tumour anatomic sites } \\
\hline Oral cavity & & $5(25.0)$ & $4(8.3)$ \\
\hline Oropharynx & & $10(50.0)$ & $44(91.7)$ \\
\hline Larynx & & $1(5.0)$ & $0(0)$ \\
\hline Hypopharynx & & $3(15.0)$ & $0(0)$ \\
\hline Nasopahrynx & & $1(5.0)$ & $0(0)$ \\
\hline \multicolumn{4}{|l|}{ Differentiation status } \\
\hline Well differentiated & & $0(0)$ & $0(0)$ \\
\hline Well to moderately differentiated & & $2(10.0)$ & $3(6.3)$ \\
\hline Moderately differentiated & & $10(50.0)$ & $9(18.8)$ \\
\hline $\begin{array}{l}\text { Moderately to poorly } \\
\text { differentiated }\end{array}$ & & $2(10.0)$ & $6(12.5)$ \\
\hline Poorly differentiated & & $3(15.0)$ & $10(20.8)$ \\
\hline $\mathrm{N} / \mathrm{A}$ & & $3(15.0)$ & $20(41.7)$ \\
\hline
\end{tabular}


in saliva differed between healthy controls and HNSCC patients as shown in Supplementary Figure 1. These data strongly support the notion that tumour biopsies can potentially be replaced by saliva in the future.

\section{The overexpression of cytokeratin 8 and 18 mRNA levels in saliva collected from HPV- negative HNSCC patients}

Current literature reports that the expression of $\mathrm{CKs}$ is able to distinguish the HPV status in HNSCC patients [31] and hence, we hypothesized that its expression in saliva will potentially have similar expression trend as in tumor biopsies. As shown in Figure 2, the mRNA expression levels of CK 8 and 18 were significantly upregulated in saliva collected from HPV-negative HNSCC patients compared to healthy controls and HPVpositive HNSCC patients. Interestingly, no significant increase in both CK 8 mRNA levels was detectable in saliva collected from HPV-positive HNSCC patients when compared to healthy controls. Most importantly, using ROC curve analysis, the mRNA expression levels of $\mathrm{CK} 8$ and 18 in saliva was able to distinguish the HPV-negative HNSCC patients from the healthy controls
(Area under the curve $($ AUC) $=0.85$, Sensitivity $80 \%$ and Specificity $86 \%$, Positive predictive values (PPV) 90.0\% and Negative predictive values (NPV) $72.7 \%$ ) as well as between HPV-negative and -positive HNSCC patients (AUC $=0.77$, Sensitivity $75 \%$ and Specificity $81 \%$, PPV $88.7 \%$ and NPV $62.5 \%$ ) as shown in Figure $3 \mathrm{~A}$ and $3 \mathrm{~B}$. These findings further support the potential clinical utility of salivary CK 8 and 18 in differential diagnosis between HPV-negative and -positive HNSCC patients.

\section{The overexpression of cytokeratin 17 and 19 mRNA levels in saliva collected from HPV- positive HNSCC}

Conversely, the mRNA expression levels of CK 17 and 19 were significantly elevated in saliva collected from HPV-positive patients compared to healthy controls as shown in Figure 2. However, the mRNA expression levels of CK 17 and 19 in saliva did not show any significant differences between healthy controls and HPV-negative HNSCC patients as well as HPV-negative and -positive HNSCC patients. Taken together, these results clearly highlight the potential diagnostic value of salivary CK 17 and 19 in discriminating the HPV status in HNSCC.
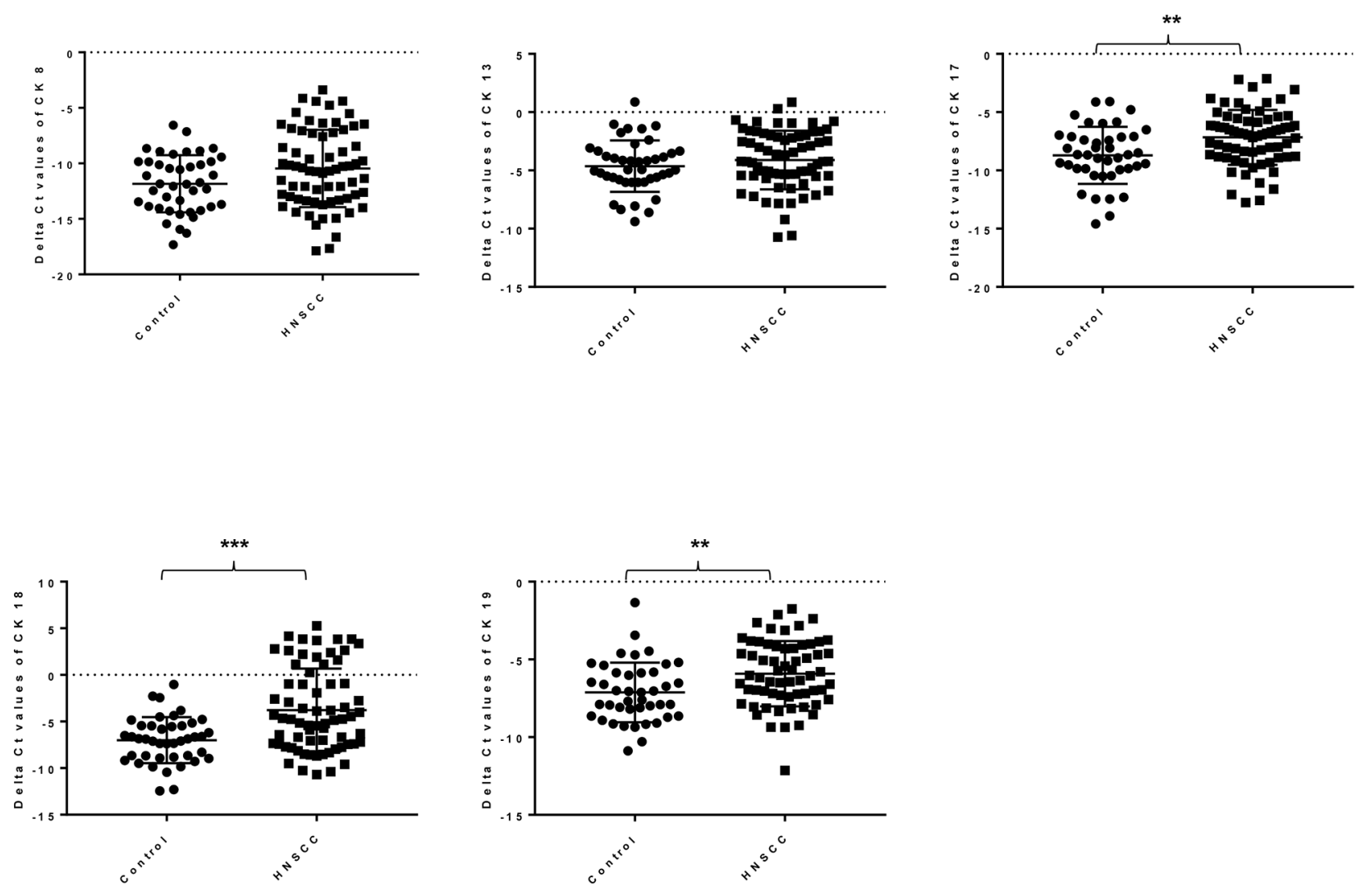

Figure 1: The mRNA relative expression level of CK 8, 13, 17, 18 and 19 in saliva collected from healthy controls $(\mathrm{n}=42)$ and HNSCC patients $(\mathbf{n}=\mathbf{6 8})$ using RT-qPCR. Results were normalized to an internal control (beta-actin) and are presented as delta $\mathrm{Ct}$ values. Statistically significant differences $(\mathrm{p}<0.05)$ were determined using Mann-Whitney U-test. $(p$ values: $* *<0.005, * * *<0.001)$. 

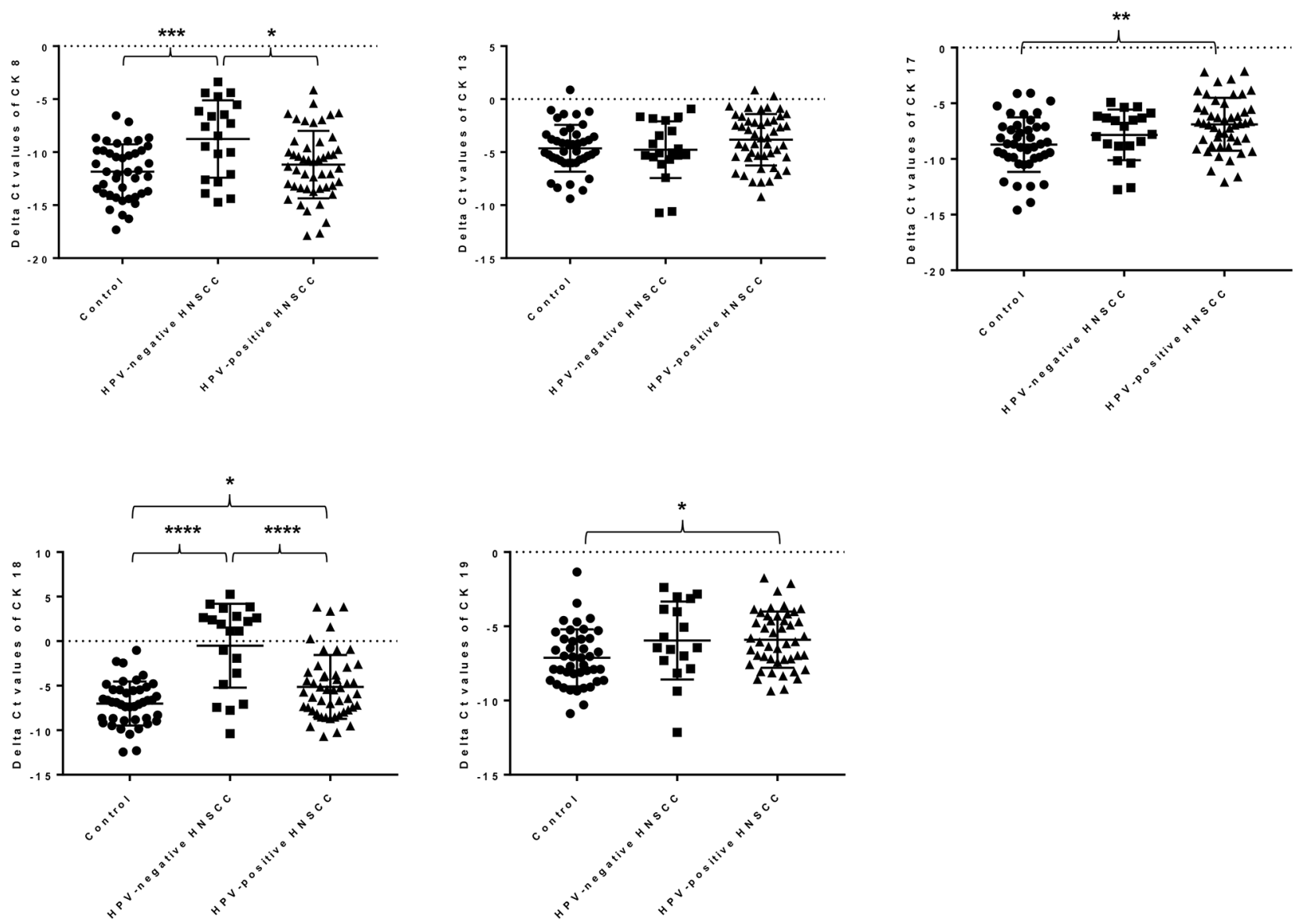

Figure 2: The mRNA relative expression level of CK 8, 13, 17, 18 and 19 in saliva collected from healthy controls $(\mathbf{n}=42)$, HPV-negative $(\mathbf{n}=\mathbf{2 0})$ and -positive HNSCC patients $(\mathbf{n}=\mathbf{4 8})$ by RT-qPCR. Results were normalized with internal control and are presented as delta Ct values. Statistically significant differences $(p<0.05)$ among these three groups were determined using ordinary one way ANOVA. ( $p$ values: $*<0.05, * *<0.005, * * *<0.001, * * * *<0.0001)$.

A.

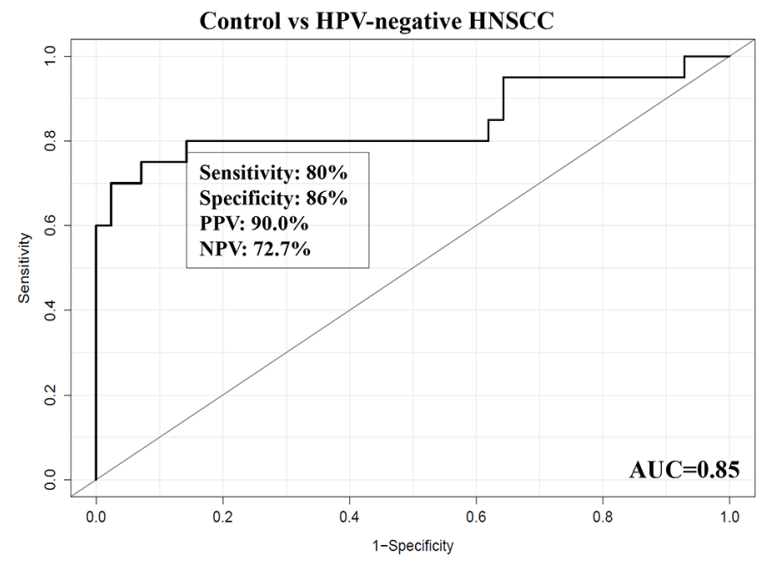

B.

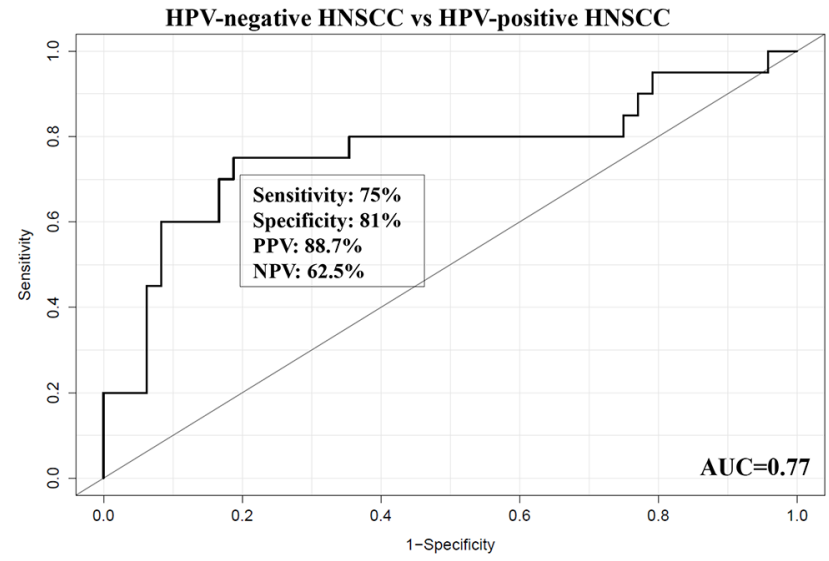

Figure 3: The receiver operator characteristic (ROC) curve analysis for the mRNA expression level of salivary CK 8 and 18 in healthy controls and HNSCC patients, indicating an area under the curve (AUC) with the diagnostic power to discriminate the HPV-negative HNSCC patients from healthy controls (A) as well as between HPV-negative and -positive HNSCC patients (B). 


\section{DISCUSSION}

The clinical diagnosis in HNSCC patients is challenging compared to other cancers as they are difficult to radiologically resolve due to the tumour size and anatomical region [13]. Therefore, diagnostic and predictive biomarkers are urgently needed to improve overall survival rates in HNSCC patients. Human saliva is a unique body fluid which has been widely used as non-invasive diagnostic markers for HNSCC [32-34]. Owing to its close proximity to the oral cavity, tumours may secrete and/or shed tumour-specific biomolecules directly into saliva. We are the first group to demonstrate that the expression profile of CKs in saliva collected from HNSCC patients is strongly correlated with blood and tissues expression levels from HNSCC patients. More importantly, the mRNA expression profile of CKs in saliva is able to discriminate the HPV-negative HNSCC from HPV-positive HNSCC.

Ample evidence has suggested that the CKs expression profile is associated with a range of different cancers including breast, colorectal, prostate and head and neck [30,35-37]. Notably, CK 8, 17 and 18 were elevated in HNSCC tumour tissues compared to normal tissues $[29,38,39]$. The circulating fragments of CK 19 were significantly increased in the serum and saliva collected from HNSCC [40-42]. Similarly, in our saliva study, compared to healthy controls, HNSCC patients expressed a higher level of CK 17, 18 and 19 mRNA. Surprisingly, there was no significant difference between the CK 8 and 13 mRNA expression levels in saliva from HNSCC patients when compared to healthy controls.

Recent studies reported that the majority of HPVpositive HNSCC tumours have distinct phenotypes. This was confirmed by our immunohistochemistry (IHC) results that most of them have a non-keratinizing morphology with basal cell features [43, 44] (data not shown), clearly demonstrating the diagnostic potential of CKs to discriminate the HPV status in HNSCC. It is worth noting that there is an association between CKs and HPV infection, but also their underlying mechanism. In both in vitro and in vivo studies, high-risk type $\mathrm{HPV}-16 \mathrm{E} 1 \wedge \mathrm{E} 4$ was found to interfere and collapse the structure of CK 8 and 18 networks in the cytoplasm [45]. Consistent with previous studies, the mRNA expression levels of CK 8 and 18 were downregulated in saliva samples collected from HPV-positive HNSCC patients compared with HPVnegative HNSCC patients.

Intriguingly, our study was in line with previous studies that observed the upregulation of CK 17 and 19 mRNA expression levels in saliva collected from HPVpositive HNSCC patients. According to Hobbs et al., CK 17 was significantly upregulated in HPV-16 mouse models compared to wild type, suggesting the possible association between HPV-16 infection and CK 17 expression [46]. Meanwhile, Favia et al. demonstrated for the first time that CK 19 induced the protein expression of HPV E7, an oncogene that plays a major role in promoting the carcinogenesis of HNSCC via the release of viral E7 mRNA from the translational block controlled by CK 7 [47]. Further evidence is supported by Santoro et al. which CK 19 suggested as a potential differential diagnostic marker to discriminate the HPV status in HNSCC [20].

Aside from being employed as a diagnostic biomarker, CKs are also found to harbour potential prognostic value in various epithelial cell-associated carcinomas [48-50]. Importantly, numerous studies have shown the significant correlation between CKs (especially 8, 18 and 19) and poor prognosis of HNSCC [50, 51], warranting further investigation. In summary, we have reported significantly elevated expression levels of CK 8 and 18 in saliva collected from HPV-negative patients, with simultaneously elevated expression levels of CK 17, 18 and 19 in saliva collected from HPV-positive HNSCC patients. A future longitudinal study is warranted to investigate the diagnostic and prognostic values of these markers.

\section{MATERIALS AND METHODS}

\section{Study design}

This study was approved by the University of Queensland Medical Ethical Institutional Board [HREC No: 2014000679 and 2014000862]; Queensland University of Technology [HREC No: 1400000617 and 1400000641] and by the Princess Alexandra Hospital Ethics Review Board [HREC Number: HREC/12/ QPAH/381]. We have recruited $(n=68)$ patients who have been diagnosed with HPV-negative and -positive HNSCC from the Princess Alexandra Hospital, Woolloongabba, Queensland, Australia. In addition, 42 cancer-free healthy controls (age-matched) were also recruited. Participants' gave written informed consent, prior to obtaining samples. Clinical stages of HNSCC patients were classified according to the Tumour-NodalMetastasis (TNM) classification of malignant tumours of the American Joint Committee on Cancer (AJCC) and the HPV status was evaluated by a pathologist using standard routine diagnostic testing of p16INK4a immunohistochemistry (IHC) as described in our previous studies [33].

\section{Oral rinse samples collection and processing}

Oral rinse samples were collected from participants as described previously [52]. Briefly, participants were asked to swish and gargle for 1-2 minutes with $10 \mathrm{ml} 0.9 \%$ saline and subsequently expectorate into a $50 \mathrm{~mL}$ falcon tube. Samples were immediately kept on dry ice and transported back to the laboratory for processing. Samples were thawed and centrifuged at $1000 \times \mathrm{g}$ for $15 \mathrm{mins}$ at 
$4{ }^{\circ} \mathrm{C}$. Cell pellets were resuspended in $800 \mu \mathrm{L}$ of Qiazol (Qiagen, Germantown, MD, USA) for RNA isolation and stored at $-80^{\circ} \mathrm{C}$ until further analysis.

\section{RNA isolation}

Total RNA was isolated from oral exfoliated cell pellets using combined method of Qiazol-Chloroform (Qiagen) and RNeasy Mini Kit (Qiagen) as per manufacturer protocol. Briefly, $130 \mu \mathrm{L}$ of chloroform was added to Qiazol containing oral exfoliated cells and centrifuged at maximum speed for 15 mins at $4{ }^{\circ} \mathrm{C}$. The resulting aqueous phase was transferred to a clean eppendorf tube with an equal volume of $70 \%$ ethanol. Then, transferred to RNeasy Mini spin columns and following the manufacturer's instructions.

\section{RT-qPCR analysis}

RNA (200 ng) was used to synthesize cDNA using the iScript cDNA Synthesis Kit (Bio-Rad, Hercules, CA, USA) following the manufacturer's instructions. qRTPCR was carried out with the QuantStudio ${ }^{\mathrm{TM}} 7$ Flex RealTime PCR System (Applied Biosystems, Foster City, CA, USA). Sense and anti-sense primers targeted against the genes of interest are listed in Supplementary Table 1. The mRNA transcript level of human beta-actin was used as a normalizer.

\section{Statistical analysis}

The mRNA expression levels of individual CKs in saliva between two cohorts (healthy controls and HNSCC patients) were compared using non-parametric analysis using Mann-Whitney U-test; while among the three cohorts (healthy controls, HPV-negative and -positive HNSCC patients) were compared using the ordinary one way ANOVA. P-values less than 0.05 were considered significant. A receiver operating characteristic (ROC) curve was used to discriminate healthy controls from HPV-negative HNSCC patients as well as between HPVnegative and -positive HNSCC patients using the salivary CKs mRNA expression levels. All the statistical analysis was performed using GraphPad Prism 7 software version 7 (GraphPad Software Inc., USA) and R Programming.

The hierarchical clustering analysis was determined using Morpheus (https://software.broadinstitute.org/ morpheus).

\section{ACKNOWLEDGMENTS}

We would like to thank Ms Dana Middleton and the staff at the ENT Department of the Princess Alexandra Hospital, Woolloongabba, Australia for their assistance in the recruitment of study patients and collection of clinical samples. We also thank Dr Yunxia Wan and
Mr Henri Schmidt for technical and editorial assistance. CP is supported by QUT VC Fellowship. This work was supported by the Queensland Centre for Head and Neck funded by Atlantic Philanthropies, the Queensland Government.

\section{CONFLICTS OF INTEREST}

The authors declare that they have no conflicts of interest.

\section{REFERENCES}

1. Kamangar F, Dores GM, Anderson WF. Patterns of cancer incidence, mortality, and prevalence across five continents: defining priorities to reduce cancer disparities in different geographic regions of the world. J Clin Oncol. 2006; 24:2137-2150.

2. Kang H, Kiess A, Chung CH. Emerging biomarkers in head and neck cancer in the era of genomics. Nat Rev Clin Oncol. 2015; 12:11-26.

3. Ferlay J, Shin HR, Bray F, Forman D, Mathers C, Parkin DM. Estimates of worldwide burden of cancer in 2008: GLOBOCAN 2008. Int J Cancer. 2010; 127:2893-2917.

4. Chaturvedi AK, Engels EA, Anderson WF, Gillison ML. Incidence trends for human papillomavirus-related and -unrelated oral squamous cell carcinomas in the United States. J Clin Oncol. 2008; 26:612-619.

5. Forte T, Niu J, Lockwood GA, Bryant HE. Incidence trends in head and neck cancers and human papillomavirus (HPV)associated oropharyngeal cancer in Canada, 1992-2009. Cancer Causes Control. 2012; 23:1343-1348.

6. Braakhuis BJ, Visser O, Leemans CR. Oral and oropharyngeal cancer in The Netherlands between 1989 and 2006: increasing incidence, but not in young adults. Oral Oncol. 2009; 45:e85-89.

7. Hammarstedt L, Dahlstrand H, Lindquist D, Onelov L, Ryott M, Luo J, Dalianis T, Ye W, Munck-Wikland E. The incidence of tonsillar cancer in Sweden is increasing. Acta Otolaryngol. 2007; 127:988-992.

8. Reddy VM, Cundall-Curry D, Bridger MW. Trends in the incidence rates of tonsil and base of tongue cancer in England, 1985-2006. Ann R Coll Surg Engl. 2010; 92:655-659.

9. Hocking JS, Stein A, Conway EL, Regan D, Grulich A, Law M, Brotherton JM. Head and neck cancer in Australia between 1982 and 2005 show increasing incidence of potentially HPV-associated oropharyngeal cancers. Br J Cancer. 2011; 104:886-891.

10. Wu XL, Tu Q, Faure G, Gallet P, Kohler C, Bittencourt Mde C. Diagnostic and prognostic value of circulating tumor cells in head and neck squamous cell carcinoma: a systematic review and meta-analysis. Sci Rep. 2016; 6:20210. 
11. Argiris A, Brockstein BE, Haraf DJ, Stenson KM, Mittal BB, Kies MS, Rosen FR, Jovanovic B, Vokes EE. Competing causes of death and second primary tumors in patients with locoregionally advanced head and neck cancer treated with chemoradiotherapy. Clin Cancer Res. 2004; 10:1956-1962.

12. Jemal A, Siegel R, Ward E, Hao Y, Xu J, Murray T, Thun MJ. Cancer statistics, 2008. CA Cancer J Clin. 2008; 58:71-96.

13. Wilken R, Veena MS, Wang MB, Srivatsan ES. Curcumin: a review of anti-cancer properties and therapeutic activity in head and neck squamous cell carcinoma. Mol Cancer. $2011 ; 10: 12$

14. Pfaffe T, Cooper-White J, Beyerlein P, Kostner K, Punyadeera C. Diagnostic potential of saliva: current state and future applications. Clin Chem. 2011; 57:675-687.

15. Chai RC, Lambie D, Verma M, Punyadeera C. Current trends in the etiology and diagnosis of HPV-related head and neck cancers. Cancer Med. 2015; 4:596-607.

16. Mohamed R, Campbell JL, Cooper-White J, Dimeski G, Punyadeera C. The impact of saliva collection and processing methods on CRP, IgE, and Myoglobin immunoassays. Clin Transl Med. 2012; 1:19.

17. Xie H, Onsongo G, Popko J, de Jong EP, Cao J, Carlis JV, Griffin RJ, Rhodus NL, Griffin TJ. Proteomics analysis of cells in whole saliva from oral cancer patients via valueadded three-dimensional peptide fractionation and tandem mass spectrometry. Mol Cell Proteomics. 2008; 7:486-498.

18. Romano V, Bosco P, Rocchi M, Costa G, Leube RE, Franke WW, Romeo G. Chromosomal assignments of human type I and type II cytokeratin genes to different chromosomes. Cytogenet Cell Genet. 1988; 48:148-151.

19. Moll R, Franke WW, Schiller DL, Geiger B, Krepler R. The catalog of human cytokeratins: patterns of expression in normal epithelia, tumors and cultured cells. Cell. 1982; 31:11-24.

20. Santoro A, Pannone G, Ninivaggi R, Petruzzi M, Santarelli A, Russo GM, Lepore S, Pietrafesa M, Laurenzana I, Leonardi R, Bucci P, Natalicchio MI, Lucchese A, et al. Relationship between CK19 expression, deregulation of normal keratinocyte differentiation pattern and high riskhuman papilloma virus infection in oral and oropharyngeal squamous cell carcinoma. Infect Agent Cancer. 2015; 10:46.

21. Moll R. Cytokeratins as markers of differentiation in the diagnosis of epithelial tumors. Subcell Biochem. 1998; 31:205-262.

22. Vaidya MM, Kanojia D. Keratins: markers of cell differentiation or regulators of cell differentiation? J Biosci. 2007; 32:629-634.

23. Sun TT, Eichner R, Nelson WG, Tseng SC, Weiss RA, Jarvinen M, Woodcock-Mitchell J. Keratin classes: molecular markers for different types of epithelial differentiation. J Invest Dermatol. 1983; 81:109s-115s.
24. Quinlan RA, Schiller DL, Hatzfeld M, Achtstatter T, Moll R, Jorcano JL, Magin TM, Franke WW. Patterns of expression and organization of cytokeratin intermediate filaments. Ann N Y Acad Sci. 1985; 455:282-306.

25. Nicolini A, Caciagli M, Zampieri F, Ciampalini G, Carpi A, Spisni R, Colizzi C. Usefulness of CEA, TPA, GICA, CA 72.4, and CA 195 in the diagnosis of primary colorectal cancer and at its relapse. Cancer Detect Prev. 1995; 19:183-195.

26. Bodenmuller H, Ofenloch-Hahnle B, Lane EB, Dessauer A, Bottger V, Donie F. Lung cancer-associated keratin 19 fragments: development and biochemical characterisation of the new serum assay Enzymun-Test CYFRA 21-1. Int J Biol Markers. 1994; 9:75-81.

27. Barak V, Goike H, Panaretakis KW, Einarsson R. Clinical utility of cytokeratins as tumor markers. Clin Biochem. 2004; 37:529-540.

28. Dahiya K, Dhankhar R. Updated overview of current biomarkers in head and neck carcinoma. World J Methodol. 2016; 6:77-86.

29. Balm AJ, Hageman PC, van Doornewaard MH, Groeneveld EM, Ivanyi D. Cytokeratin 18 expression in squamous cell carcinoma of the head and neck. Eur Arch Otorhinolaryngol. 1996; 253:227-233.

30. Xu XC, Lee JS, Lippman SM, Ro JY, Hong WK, Lotan $\mathrm{R}$. Increased expression of cytokeratins CK8 and CK19 is associated with head and neck carcinogenesis. Cancer Epidemiol Biomarkers Prev. 1995; 4:871-876.

31. El-Mofty SK, Patil S. Human papillomavirus (HPV)-related oropharyngeal nonkeratinizing squamous cell carcinoma: characterization of a distinct phenotype. Oral Surg Oral Med Oral Pathol Oral Radiol Endod. 2006; 101:339-345.

32. Salazar C, Nagadia R, Pandit P, Cooper-White J, Banerjee N, Dimitrova N, Coman WB, Punyadeera C. A novel salivabased microRNA biomarker panel to detect head and neck cancers. Cell Oncol (Dordr). 2014; 37:331-338.

33. Chai RC, Lim Y, Frazer IH, Wan Y, Perry C, Jones L, Lambie D, Punyadeera C. A pilot study to compare the detection of HPV-16 biomarkers in salivary oral rinses with tumour p16(INK4a) expression in head and neck squamous cell carcinoma patients. BMC Cancer. 2016; 16:178.

34. Lim Y, Wan Y, Vagenas D, Ovchinnikov DA, Perry CF, Davis MJ, Punyadeera C. Salivary DNA methylation panel to diagnose HPV-positive and HPV-negative head and neck cancers. BMC Cancer. 2016; 16:749.

35. Abd El-Rehim DM, Pinder SE, Paish CE, Bell J, Blamey RW, Robertson JF, Nicholson RI, Ellis IO. Expression of luminal and basal cytokeratins in human breast carcinoma. J Pathol. 2004; 203:661-671.

36. Chu P, Wu E, Weiss LM. Cytokeratin 7 and cytokeratin 20 expression in epithelial neoplasms: a survey of 435 cases. Mod Pathol. 2000; 13:962-972.

37. Knosel T, Emde V, Schluns K, Schlag PM, Dietel M, Petersen I. Cytokeratin profiles identify diagnostic 
signatures in colorectal cancer using multiplex analysis of tissue microarrays. Cell Oncol. 2006; 28:167-175.

38. Matthias C, Mack B, Berghaus A, Gires O. Keratin 8 expression in head and neck epithelia. BMC Cancer. 2008; 8:267.

39. Kitamura R, Toyoshima T, Tanaka H, Kawano S, Kiyosue T, Matsubara R, Goto Y, Hirano M, Oobu K, Nakamura S. Association of cytokeratin 17 expression with differentiation in oral squamous cell carcinoma. J Cancer Res Clin Oncol. 2012; 138:1299-1310.

40. Malhotra R, Urs AB, Chakravarti A, Kumar S, Gupta VK, Mahajan B. Correlation of Cyfra 21-1 levels in saliva and serum with CK19 mRNA expression in oral squamous cell carcinoma. Tumour Biol. 2016; 37:9263-9271.

41. Rajkumar K, Ramya R, Nandhini G, Rajashree P, Ramesh Kumar A, Nirmala Anandan S. Salivary and serum level of CYFRA 21-1 in oral precancer and oral squamous cell carcinoma. Oral Dis. 2015; 21:90-96.

42. Zhong LP, Zhang CP, Zheng JW, Li J, Chen WT, Zhang ZY. Increased Cyfra 21-1 concentration in saliva from primary oral squamous cell carcinoma patients. Arch Oral Biol. 2007; 52:1079-1087.

43. Westra WH. The changing face of head and neck cancer in the 21st century: the impact of HPV on the epidemiology and pathology of oral cancer. Head Neck Pathol. 2009; 3:78-81.

44. Gillison ML, Koch WM, Capone RB, Spafford M, Westra WH, Wu L, Zahurak ML, Daniel RW, Viglione M, Symer DE, Shah KV, Sidransky D. Evidence for a causal association between human papillomavirus and a subset of head and neck cancers. J Natl Cancer Inst. 2000; 92:709-720.

45. Wang Q, Griffin H, Southern S, Jackson D, Martin A, McIntosh P, Davy C, Masterson PJ, Walker PA, Laskey P, Omary MB, Doorbar J. Functional analysis of the human papillomavirus type $16 \mathrm{E} 1=\mathrm{E} 4$ protein provides a mechanism for in vivo and in vitro keratin filament reorganization. J Virol. 2004; 78:821-833.

46. Hobbs RP, Batazzi AS, Han MC, Coulombe PA. Loss of Keratin 17 induces tissue-specific cytokine polarization and cellular differentiation in HPV16-driven cervical tumorigenesis in vivo. Oncogene. 2016; 35:5653-5662.

47. Favia G, Kanduc D, Lo Muzio L, Lucchese A, Serpico R. Possible association between HPV16 E7 protein level and cytokeratin 19. Int J Cancer. 2004; 111:795-797.

48. van Dalen A, Favier J, Burges A, Hasholzner U, de Bruijn HW, Dobler-Girdziunaite D, Dombi VH, Fink D, Giai M, McGing P, Harlozinska A, Kainz C, Markowska J, et al. Prognostic significance of CA 125 and TPS levels after 3 chemotherapy courses in ovarian cancer patients. Gynecol Oncol. 2000; 79:444-450.

49. Makino T, Yamasaki M, Takeno A, Shirakawa M, Miyata H, Takiguchi S, Nakajima K, Fujiwara Y, Nishida T, Matsuura N, Mori M, Doki Y. Cytokeratins 18 and 8 are poor prognostic markers in patients with squamous cell carcinoma of the oesophagus. Br J Cancer. 2009; 101:1298-1306.

50. Fillies T, Werkmeister R, Packeisen J, Brandt B, Morin P, Weingart D, Joos U, Buerger H. Cytokeratin 8/18 expression indicates a poor prognosis in squamous cell carcinomas of the oral cavity. BMC Cancer. 2006; 6:10.

51. Ernst J, Ikenberg K, Apel B, Schumann DM, Huber G, Studer G, Rordorf T, Riesterer O, Rossle M, Korol D, Bredell MG. Expression of CK19 is an independent predictor of negative outcome for patients with squamous cell carcinoma of the tongue. Oncotarget. 2016; 7:7615176158. https://doi.org/10.18632/oncotarget.12691.

52. Sun CX, Bennett N, Tran P, Tang KD, Lim Y, Frazer I, Samaranayake L, Punyadeera C. A pilot study into the association between oral health status and human papillomavirus-16 infection. Diagnostics (Basel). 2017; 7:E11. 